\title{
Reserve for Arabian Oryx
}

\section{John Clarke}

The wildlife of the Jordanian deserts was shot out in the 1950s. As a first step towards restoring it, the Royal Society for the Conservation of Nature in Jordan has set up a captive breeding unit at its Shaumari Reserve, eight miles from the great oasis of Azraq. Though the first occupants are likely to be gazelles, by the time this issue appears there may well be four male Arabian oryx also. These, the foundation of what it is hoped will be the first captive herd of Arabian oryx in Arabia deriving from Operation Oryx, have been presented to Jordan by the Trustees of the World Herd of Arabian Oryx, now located at Phoenix and San Diego Zoos in the USA. There are a number of other captive herds of local origin already in the Arabian peninsula, including the well known one in Qatar.

Ten years ago, Jordan's hopes and plans for wildlife conservation, following the slaughter of the $1950 \mathrm{~s}$, were described in $\operatorname{Oryx} .{ }^{1}$ Fulfilment of these hopes rested with the Royal Jordanian Hunting Club, which had an ambitious programme both to protect the surviving fauna and to re-establish in the wild animals that had become, or were close to becoming, locally extinct. Then came the traumatic war years. But the Club retained its hopes, changed its name to the Royal Society for the Conservation of Nature, and embarked upon its programme. This is now concentrated on the establishment of a small but valuable desert reserve with a special purpose.

To carry out its plans for breeding animals that had become locally extinct or endangered in order to re-establish them in the wild, the Society acquired, for a breeding centre, a $22-\mathrm{sq}-\mathrm{km}$ tract of semi-desert or badia, called Shaumari, about $118 \mathrm{~km}$ from Amman by road, which until 1964 had been an experimental agricultural station. Dr Bryan Nelson, who in 1968/69 was setting up the Jordan International Biological Station at Azraq, $13 \mathrm{~km}$ away, described Shaumari as 'possibly the greatest single asset that the Station could have'. ${ }^{4}$ But owing to the political troubles, the Station failed to materialise and Shaumari lay unused. 
In 1974, the Royal Society started again, and arranged for Wayne Homan, Curator of Mammals of the Phoenix Zoo, where the World Herd of Arabian oryx was building up, to inspect Shaumari. His report described the reserve as offering nearly ideal conditions for a first-phase programme to re-establish Arabian oryx Oryx leucory $x$ in the wild. The World Wildlife Fund agreed to provide two Toyota Landcruisers and the services for two years of a Project Leader responsible for setting up breeding facilities, preparing a reserve management plan and training local staff; he was also to study the Azraq region with a view to up-dating the draft management plan for the proposed Azraq national park, ${ }^{2}$ and to advise the Royal Society and other Jordanian authorities on conservation and national parks.

The project began in October 1975, and since then the area has been brought to full reserve status and named the Shaumari Wildlife Reserve. The first of its kind in Jordan, it fulfils all the criteria for inclusion in the UN List of National Parks and Equivalent Reserves. A new, well-equipped administrative headquarters houses four staff members. The reserve has been mapped, an inventory made of its floral and faunal resources, a herbarium started and detailed records are kept of mammals and birds. The most costly item was an animal holding unit, adequate for keeping animals up to the size of Arabian oryx, although the first inmates may well be gazelles - Gazella dorcas and G. subgutturosa. The unit, completed in June 1976 , measures $154 \times 80 \mathrm{~m}$; it contains five herd enclosures of $120 \times 10 \mathrm{~m}$ each, ten isolation pens for females with young, and a large food store. It is surrounded by a predatorproof, galvanised steel mesh fence (hyaenas occur in the vicinity). The enclosure and pens are fed by an underground water reticulation system.

The reserve covers 22 square kilometres, about $11 \mathrm{~km}$, in a straight line, from Azraq Oasis. The terrain is fairly flat, the altitude varying around the $530 \mathrm{~m}$ level. A hot, dry summer and a cold winter with very little precipitation are typical, with annual rainfall averaging a little over $50 \mathrm{~mm}$. A third of the reserve is on limestone hammada where the surface is thickly strewn with cherty and flinty pebbles and plant growth is sparse; the remainder consists of sandy surfaced wadi spread, through which water flows during and immediately after rain; plant cover in the wadis is surprisingly rich. A barbedwire fence to exclude domestic animals ensures a vigorous plant growth compared with outside where camels, sheep, goats and donkeys are numerous. Up to mid-1976, 151 plant species had been identified with at least a further twenty still to be determined, all flowering plants except for one gymnosperm and two fungi. The family Chenopodiaceae predominates with species such as Atriplex halimus, Anabasis articulata, Seidlitzia rosmarinus and Salsola baryosma; Compositae, Gramineae and Leguminosae are also well represented. Six mammals have been recorded: red fox Vulpes vulpes, three-toed jerboa Jaculus jaculus, Wagner's gerbil Gerbillus dasyurus, Ethiopian hedgehog Paraechinus aethiopicus, brown hare Lepus capensis and house mouse Mus musculus.

Birds are the most conspicuous vertebrates: 117 species have been observed, of which only about ten are residents throughout the year. The Shaumari Wildlife Reserve is a remarkable place to observe migration. Most of the migrants passing through, of which swallows Hirundo rustica and sand martins Riparia riparia are the most abundant, concentrate in half a square kilometre of land close by the reserve headquarters where there are trees and water (pumped to the surface for irrigation and domestic use). 
Right SHAUMARI WILDLIFE RESERVE showing the improved plant growth

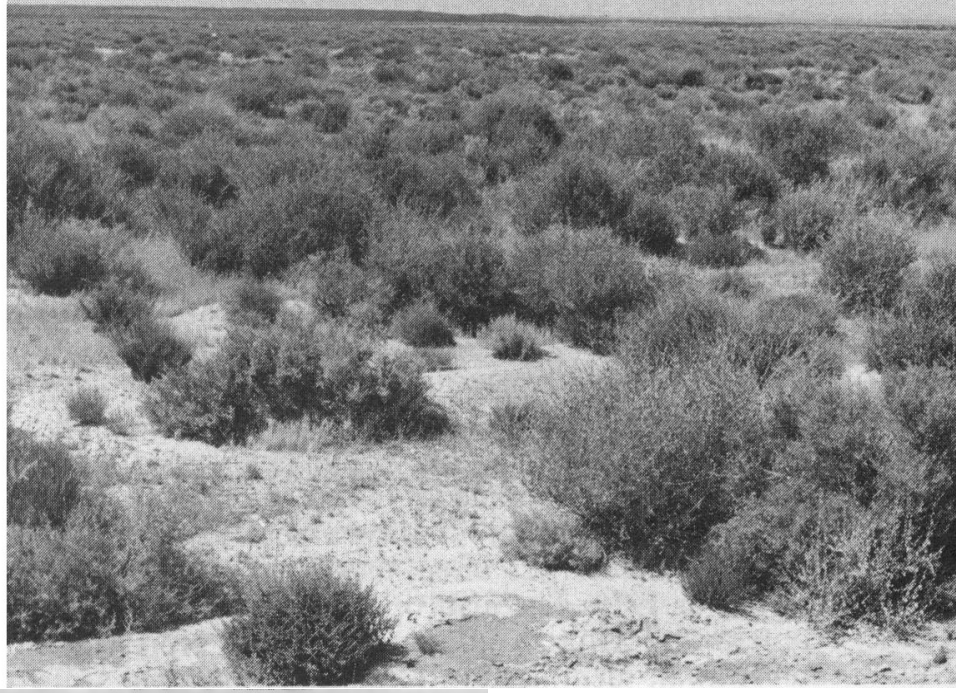

HEADQUARTERS of the reserve

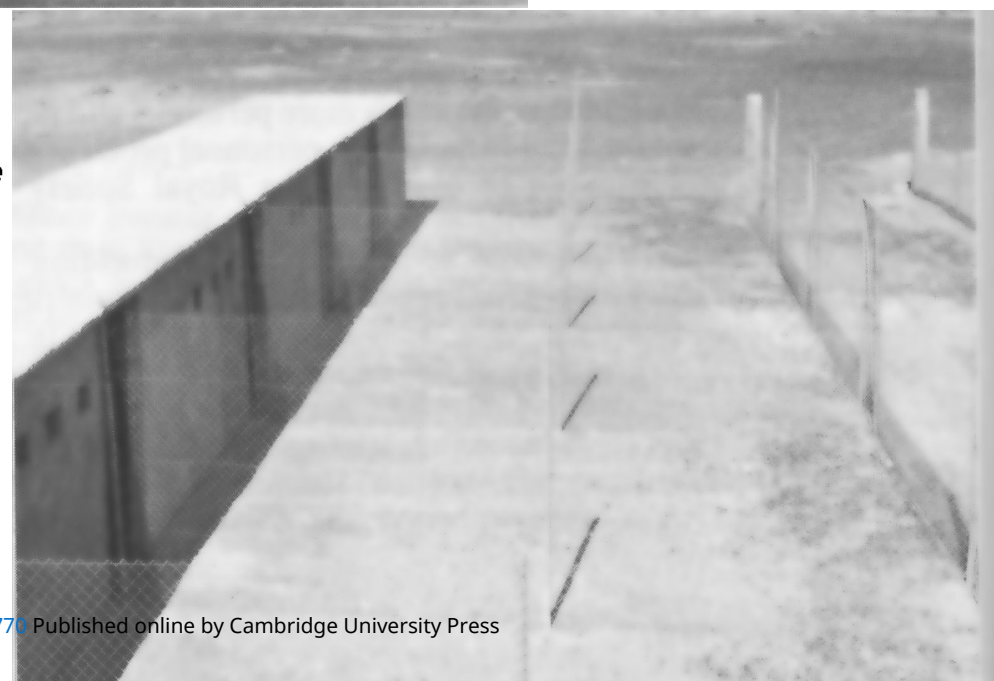


Resident breeding birds include several larks; Temminck's horned Eremophila bilopha, bifasciated or hoopoe Alaemon alaudipes, lesser short-toed Calendrella rufescens, desert Ammomanes deserti and crested Galerida cristata plus great grey shrike Lanius excubitor, scrub warbler Scotocerca inquieta and desert wheater Oenanthe deserti. Species which breed in the reserve but move out afterwards include cream-coloured courser Cursorius cursor and rufous bushchat Cercotrichas galactotes. Birds wintering in Shaumari include white wagtail Motacilla alba, stonechat Saxicola torquata and Finsch's wheatear Oenanthe finschii. The endangered houbara bustard Chlamydotis undulata is found occasionally. Over a twelve-month period the author saw this bird on eight occasions inside the reserve (thirteen individuals) and twice outside (eight individuals).

Little is known about the herpetology. Lizards are commonly seen in summer, snakes less often, and one unidentified toad was recorded in the spring of 1976. The arthropod fauna is abundant, and Lepidoptera, Coleoptera and Diptera appear to be well represented, but further comment must await identification of collected material sent to the British Museum. Of special interest is a large species of barrel spider or wind scorpion (order Solifuges) which runs about actively during summer nights seeking its prey. One specimen had a body length of $9 \mathrm{~cm}$. The amount of research and conservation education that can be done at Shaumari will depend upon the encouragement given to research and teaching institutes, especially the University of Jordan. There is good visitor accommodation in the Royal Society's lodge at Azraq (thirty people), and a new government hotel takes over forty. Access is easy since Shaumari is close to Azraq which is well on the way to becoming the crossroads of the Middle East. The trans-Arabian highway, joining Syria, Iraq, Saudi Arabia and the Gulf States, passes six kilometres away with heavy traffic even from Western Europe, and work has started on another highway to the north which will give more direct access to Iraq. There are also plans for a road to the south-west which will make for a direct link with the Red Sea port of Aqaba. In view of Shaumari's remoteness it is interesting that one can drive the whole way from Europe to the entrance gate on tarred roads.

This accessibility could of course be hazardous for the future integrity of the reserve. The Royal Society will have to exercise visitor control, particularly when its captive breeding programme gets under way, and reject the temptations to develop the reserve as a tourist amenity, keeping the conservation interests firmly in sight. But, above all, to ensure long-term management, the Society needs more personnel and more money. The lack of enthusiasm for wildlife makes the personnel problem a difficult one, but until these problems can be overcome the Royal Society may need continued outside support.

Shaumari's potential as a conservation education centre may prove its most fruitful long-term function. Some Arab countries have shown interest in using Shaumari as a training school for wildlife managers; any international co-operation of this nature ought to be welcomed. Research opportunities are considerable, and many facets of arid zone ecology could be investigated there including, later on, feeding and nutrition studies with the reintroduced animals - ostrich Struthio camelus, cheetah Acinonyx jubatus, onager Equus hemionus onager and Asiatic lion Panthera leo persica are just 
a few of the possibilities. There could be exciting times ahead for this, as yet, little known reserve.

\section{References}

1. FITTER, M., 1967. New hope for wildlife in Jordan. Oryx 9: 35-38.

2. HEMSLEY, J. H. and GEORGE, M., 1966. Azraq desert national park, Jordan. Draft management plan. Unpublished report issued by IBP/CT Section, London.

3. HOMAN, W. G., 1974. A feasibility study of Shaumari, Jordan, as a breeding farm for endemic animals. Unpublished report issued by the Phoenix Zoo, Arizona.

4. NELSON, J. B., 1973. Azraq: desert oasis. Allen Lane, London.

\section{Migratory Birds Commonly seen at Shaumari:}

Swallow
Sand martin
Lesser kestrel
Black-bellied
sandgrouse
Turtle dove
Swift
Bee-eater
Roller
Hoopoe
Yellow wagtail
Masked shrike
Woodchat shrike
Red-backed shrike
Olivaceous warbler
Whitethroat
Lesser whitethroat
Blackcap
Willow warbler
Chiffchaff
Spotted flycatcher
Wheatear
Isabelline wheatear
Black-eared wheatear
Redstart
Ortolan
Golden oriole

Hirundo rustica

Riparia riparia

Falco naumanni

Pterocles orientalis

Streptopelia turtur

Apus apus

Merops apiaster

Coracias garrulus

Upupa epops

Motacilla flava

Lanius nubicus

L. senator

L. collurio

Hippolais pallida

Sylvia communis

S. curruca

S. atricapilla

Phylloscopus trochilus

$P$. collybita

Muscicapa striata

Oenanthe oenanthe

O. isabellina

$O$. hispanica

Phoenicurus phoenicurus

Emberiza hortulana

Oriolus oriolus

\section{Man is not always Vile}

The white-tailed kite Elanus leucurus, which once ranged from northern California to Central America and then, like many other animals, was nearly wiped out by 1900 , is making a comeback in the California plains and the foothills of the Sierra Nevada, thanks mainly to man-made changes. These include an increase in voles due to irrigation of formerly dry grassland; land speculation after the war, which for many years left tracts uncultivated; modern fire-control methods that tend to transform rodent-poor chaparral areas into grassland; and the appearance of the feral house mouse, giving the bird alternative prey. Many farmers still consider the bird a threat to poultry, but legal protection has prevented any slaughter on the nineteenth-century scale. 